\title{
Portulaca oleracea seeds extract does not prevent dexamethasone-induced hypertension in rats
}

\author{
Leila Safaeian $^{1^{*}}$, Bahar Baniahmad ${ }^{2}$, Zahra Esfandiari $^{3}$, Sayed Ali Alavi ${ }^{4}$ \\ ${ }^{1}$ Department of Research and Development, Vice Chancellery for Food and Drug, Department of Pharmacology and Toxicology, School of Pharmacy \\ and Pharmaceutical Sciences, Isfahan University of Medical Sciences, Isfahan, Iran \\ ${ }^{2}$ Department of Pharmacology and Toxicology, Isfahan Pharmaceutical Sciences Research Center, School of Pharmacy and Pharmaceutical Sciences, \\ Isfahan University of Medical Sciences, Isfahan, Iran \\ ${ }^{3}$ Department of Research and Development, Vice-Chancellery for Food and Drug, Isfahan University of Medical Sciences, Isfahan, Iran \\ ${ }^{4}$ Hakiman Shargh Investigative Corporation, Isfahan Science and Technology Town, Isfahan, Iran
}

\section{A R T I C L E I N F O}

Article Type:

Short Communication

Article History:

Received: 10 October 2017

Accepted: 2 December 2017

Keywords:

Portulaca oleracea

Hypertension

Dexamethasone

\begin{abstract}
A B S T R A C T
Introduction: Portulaca oleracea is used as a nutritional and medicinal plant. The aim of this study was to assess the effect of hydroalcoholic extract of $P$. oleracea seeds in dexamethasone -induced hypertension in rats.

Methods: For induction of hypertension, dexamethasone $(30 \mu \mathrm{g} / \mathrm{kg} / \mathrm{d}$, subcutaneously) was administered for 14 days. Animals received P. oleracea extract as a pretreatment at various doses of 100,200 and $400 \mathrm{mg} / \mathrm{kg} / \mathrm{d}$ orally from 4 days before dexamethasone administration and during the test period. Systolic blood pressure (SBP) and heart rate were measured using tailcuff method. The weight of thymus gland was estimated as a marker of glucocorticoid activity. Results: Dexamethasone injection significantly increased SBP $(P<0.001)$ while decreased the body and thymus weights $(P<0.05$ and $P<0.001$, respectively). Oral administration of $P$. oleracea could not prevent rising in SBP and decreasing in thymus weight. It also increased heart rate in hypertensive rats at the dose of $400 \mathrm{mg} / \mathrm{kg} / \mathrm{d}(P<0.05)$.

Conclusion: The results of this study revealed that hydroalcoholic extract of $P$. oleracea seeds aggregates hypertension in dexamethasone-induced hypertensive rats. Hence, it should be used with caution in hypertensive patients receiving glucocorticoids.
\end{abstract}

Implication for health policy/practice/research/medical education:

The results of this study revealed that hydroalcoholic extract of $P$. oleracea seeds aggregates hypertension in dexamethasoneinduced hypertensive rats. Therefore, it is recommended that its using be avoided in hypertensive patients receiving glucocorticoids. Please cite this paper as: Safaeian L, Baniahmad B, Esfandiari Z, Alavi SA. Portulaca oleracea seeds extract does not prevent dexamethasone-induced hypertension in rats. J Herbmed Pharmacol. 2018;7(1):8-12. doi: 10.15171/jhp.2018.02.

\section{Introduction}

Hypertension or high blood pressure is a common global health problem. According to the statistical report of the World Health Organization (WHO) in 2015, about 24.0\% of male and $20.5 \%$ of female subjects suffer from high blood pressure worldwide. There is also a high prevalence of hypertension in Iran and this vascular disease affects $24.1 \%$ of Iranian male and $23.3 \%$ of Iranian female subjects above 18 years old (1). Hypertension is an important cause for dangerous disorders in major end-organs such as ischemic heart diseases, stroke and renal failure (2). The early diagnosis of hypertension and its medical treatment along with a change in life style would be associated with a decline in the risk of cardiovascular events (3). However, high blood pressure is properly managed only in less than $30 \%$ of patients and many people complain of side effects of conventional antihypertensive drugs (4). Recent studies have reported the preventive and helpful effects of various herbal medicines in cardiovascular diseases including hypertension (5).

Portulaca oleracea L. commonly known as purslane belongs to the Portulacea family. This annual succulent herb is growing throughout the Old World and used as a salad and vegetable in many countries (6). Wide 
range of pharmacological properties has been reported for various extracts of $P$. oleracea including antioxidant, antibacterial, hepatoprotective, analgesic, muscle relaxant, anti-inflammatory, bronchodilatory, antihyperglycemic, antihyperlipidemic and anticancer activities (6-11). Some investigations have proposed the potential of this herbal medicine for protection against cardiovascular diseases (12).

In this study, an attempt was made to determine the effect of hydroalcoholic extract of $P$. oleracea seeds in dexamethasone-induced hypertension in rats.

\section{Methods}

Animals

Male Wistar rats weighing 180 to 220 g were randomly selected from the animal house of the School of Pharmacy and Pharmaceutical Sciences (Isfahan, Iran). The animals were kept under standard laboratory conditions including $12 \mathrm{~h}$ light $/ 12 \mathrm{~h}$ dark cycle and room temperature of 20 $25^{\circ} \mathrm{C}$ with free access to water and standard animal diet.

\section{Chemicals}

Captopril was purchased from Tehran Darou Pharmaceutical Co. (Tehran, Iran) and dexamethasone was obtained from Darou Pakhsh Pharmaceutical Co. (Tehran, Iran).

Plant material and preparation of the extract

The $P$. oleracea seeds were purchased from a local market of medicinal plants in Isfahan, Iran, and authenticated by Dr Ghaemmaghami (Department of Biology, School of Science, University of Isfahan). A voucher specimen (No. 1891) was deposited at the Herbarium of the School of Pharmacy and Pharmaceutical Sciences, Isfahan, Iran. For the preparation of hydroalcoholic extract, the powdered seeds of plant were extracted with ethanol (70\%), using maceration method for 72 hours at room temperature. After completion of extraction (3 times), the solvent was removed by a rotary evaporator under low pressure at $50^{\circ} \mathrm{C}$ to yield a viscous residue. The obtained extract was stored at $-20^{\circ} \mathrm{C}$.

\section{Experimental design}

For induction of hypertension, dexamethasone $(30 \mu \mathrm{g} /$ $\mathrm{kg} / \mathrm{d}$ ) was injected subcutaneously (s.c.) in rats for 14 days, and the control group received daily s.c. injection of normal saline $(1 \mathrm{~mL} / \mathrm{kg})$. In this prevention study, animals received $P$. oleracea seeds extract (100, 200 and $400 \mathrm{mg} /$ $\mathrm{kg}$ ) or captopril $(40 \mathrm{mg} / \mathrm{kg}$, an antihypertensive agent as a reference drug) orally using an intra-gastric tube from 4 days before dexamethasone administration and during the test period (days 1-18). Six rats were used in each group. All animals were weighted on alternate days. At the end of the experiment, the rats were sacrificed under ether anesthesia and the thymus glands were isolated. The weight of thymus was measured and expressed as milligrams per $100 \mathrm{~g}$ body weight. Decline in thymus weight was considered as a marker of glucocorticoid activity $(13,14)$.

Measurement of systolic blood pressure and heart rate The systolic blood pressure (SBP) and heart rate were recorded by non-invasive tail-cuff method (AD Instrument PowerLab Data Acquisition System, Australia) at the first and last days of the experiment in conscious rats. Ten minutes before measurements, each animal was restrained in a heated chamber at $38 \pm 1^{\circ} \mathrm{C}$. A training period of 1 week was established before the experiment to allow the rats become adapted to the procedure. Five measurements of blood pressure and heart rate were taken for each rat and their averages were used to obtain the mean values.

\section{Statistical analysis}

All values were shown as the mean \pm standard error of mean (SEM). For statistical evaluation, one-way analysis of variance (ANOVA) followed by Tukey post hoc test was used (SPSS software version 18.0). Differences with a value of $P<0.05$ were considered to be significant.

\section{Results}

Effect of Portulaca oleracea seeds extract on blood pressure Administration of dexamethasone significantly increased SBP from $116.3 \pm 2.7$ to $152.6 \pm 3.6 \mathrm{mmHg}(P<0.001)$ compared to the normal control group $(122.5 \pm 1.5 \mathrm{~mm}$ $\mathrm{Hg})$. Captopril caused a significant decrease in SBP $(P$ $<0.001)$ but pretreatment with $P$. oleracea seeds extract could not prevent the increase in SBP (Figure 1).

Effect of Portulaca oleracea seeds extract on heart rate As shown in Figure 2, heart rate was not significantly changed after administration of dexamethasone, captopril or $P$. oleracea seeds extract at the doses of 100 and 200 $\mathrm{mg} / \mathrm{kg}$. However, treatment with $400 \mathrm{mg} / \mathrm{kg}$ of $P$. oleracea seeds extract caused a significant increase in rats heart

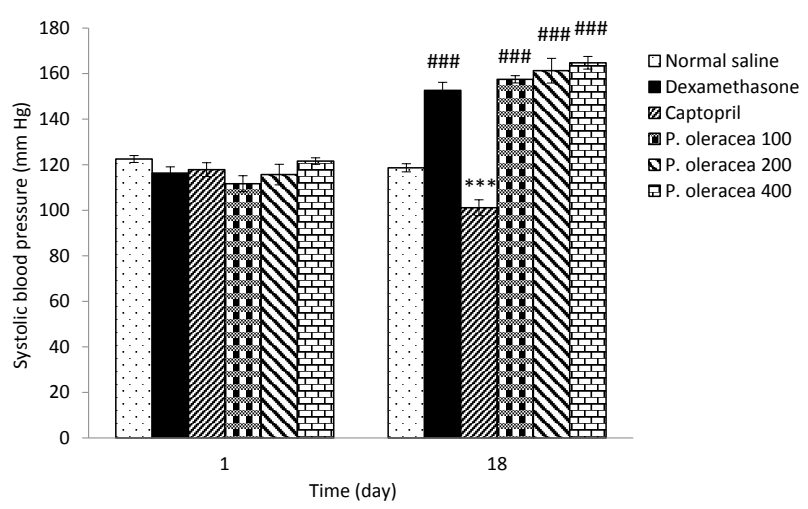

Figure 1. Effects of $P$. oleracea seeds extract and captopril (40 $\mathrm{mg} / \mathrm{kg}$ ) on systolic blood pressure in dexamethasone-induced hypertensive rats. Values are means $\underline{\underline{ }}$ SEM for six rats. ${ }^{\# \#} P$ $<0.001$ versus normal saline group, and "*t $P<0.001$ versus dexamethasone group. 


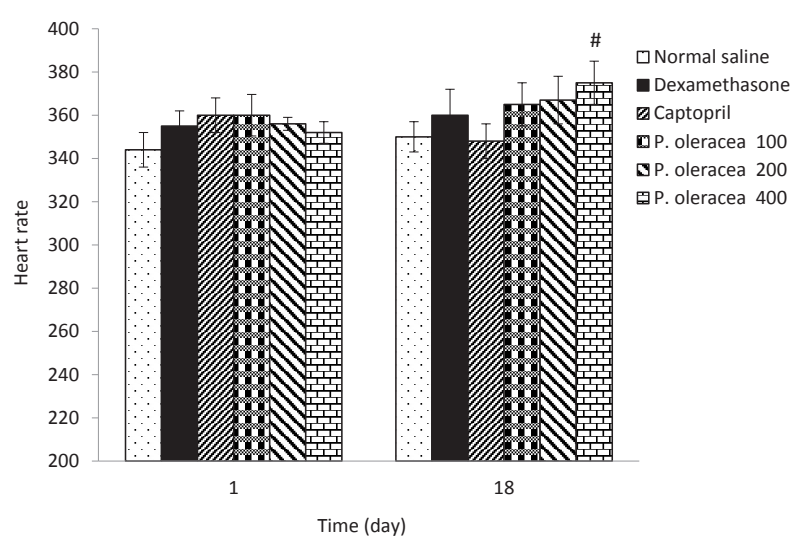

Figure 2. Effects of $P$. oleracea seeds extract and captopril (40 $\mathrm{mg} / \mathrm{kg}$ ) on heart rate in dexamethasone-induced hypertensive rats. Values are means \pm SEM for six rats. ${ }^{\#} P<0.05$ versus normal saline control group.

rate compared to the normal control group $(P<0.05)$.

Effect of Portulaca oleracea seeds extract on body weight Dexamethasone injection caused a significant decrease in body weight in hypertensive animals compared to normal control group $(P<0.05)$. Administration of $P$. oleracea seeds extract significantly increased weight loss at all doses. However, captopril could prevent body weight loss induced by dexamethasone $(P<0.05$, Figure 3$)$.

Effect of Portulaca oleracea on thymus weight Administration of dexamethasone significantly reduced the thymus gland weight as a marker of glucocorticoid activity in hypertensive rats $(P<0.001)$. Treatment with $P$. Oleracea seeds extract and captopril could not prevent the thymus weight decline (Figure 4).

\section{Discussion}

The present study investigated the effect of hydroalcoholic extract of $P$. oleracea seeds on blood pressure in the animal model of dexamethasone-induced hypertension in rats. The results showed that oral administration of $P$. Oleracea seeds extract could not prevent rising in SBP.

Chronic use of dexamethasone leads to hypertension through various mechanisms including increased activity of cardiovascular regulating systems such as sympathetic, renin-angiotensin and endothelin systems and changing in hemodynamic status (15). Augmented sensitivity and reactivity to angiotensin II and norepinephrine and subsequently increased vascular resistance have been defined following dexamethasone administration (16). The roles of oxidative stress and over-production of reactive oxygen species (ROS) through nicotinamide adenine dinucleotide phosphate (NAPDH) oxidase pathway and nitric oxide (NO) deficiency have also been implicated in the pathophysiology of glucocorticoidinduced hypertension (17). Some antioxidant agents and herbal medicines have been able to prevent and reduce

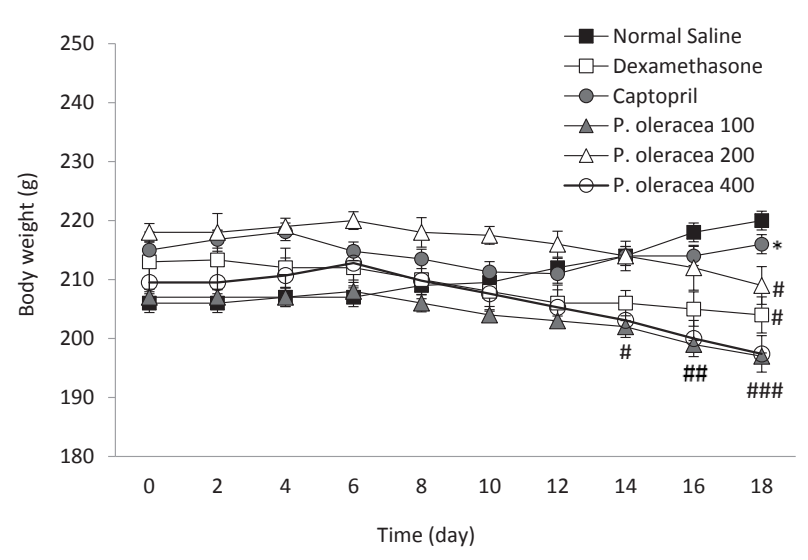

Figure 3. Effects of $P$. oleracea seeds extract and captopril (40 $\mathrm{mg} / \mathrm{kg}$ ) on body weight in dexamethasone-induced hypertensive rats. Values are means \pm SEM for six rats. ${ }^{\#} P<0.05,{ }^{\#} P<0.01$ and ${ }^{\# \#} P<0.001$ versus normal saline control group and ${ }^{*} P<0.05$ versus dexamethasone group.

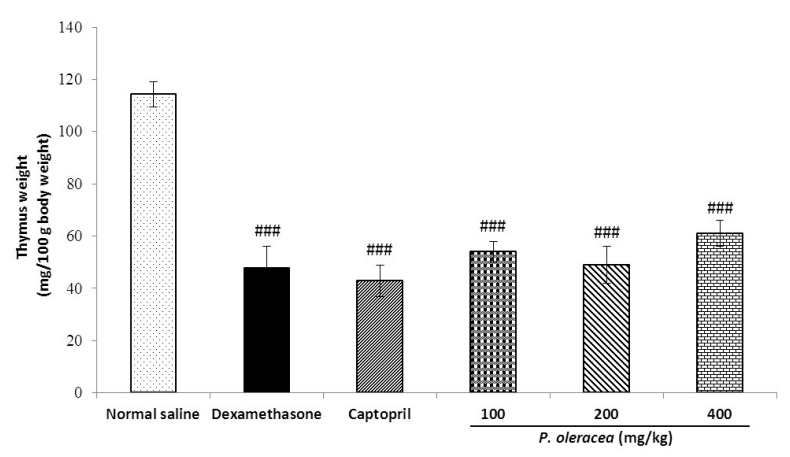

Figure 4. Effects of $P$. oleracea seeds extract and captopril (40 mg/ $\mathrm{kg}$ ) on thymus weight in dexamethasone-induced hypertensive rats. Values are means \pm SEM for six rats. ${ }^{\# \#} P<0.001$ versus normal saline control group

hypertension from dexamethasoneinvariousinvestigations (18). The hydroalcoholic extract of stems and green leaves of $P$. oleracea has been reported to have antihypertensive activity with negative ionotropic and chronotropic effects (19). Phytochemical analysis of P. oleracea demonstrated the presence of flavonoids, terpenoids, coumarins, alkaloids, sterols and various nutrients including calcium, magnesium, thiamin, riboflavin, nicotinic acid, vitamin C, carotene, vitamin E, fatty acids, omega-3, linolenic acid, oxalic acid and others $(20,21)$. Its aerial parts are also rich in potassium ions elucidating the muscle relaxant effect of $P$. oleracea (8). There are also valid documents for the presence of biologically active catecholamines including noradrenaline, dopamine and L-dopa in P. oleracea. Large concentrations of noradrenaline in the fresh plant have been reported as $2.5 \mathrm{mg} / \mathrm{g}$ which is probably larger than that of extractable amount from the mammalians suprarenal glands (22). These neurotransmitters may be responsible for increasing blood pressure in this model of hypertension in which dexamethasone intensifies the reactivity to vasopressor effects of catecholamines.

There is no accurate data for toxicity profile of seeds 
of $P$. oleracea, however Musa and coworkers reported moderate toxicity and LD50 about $1853-1875 \mathrm{mg} / \mathrm{kg}$ for methanolic extract of $P$. oleracea (23). There are some reports for the alteration in oxalic acid content in $P$. oleracea extract based on the nitrogen concentration and nitrate/ammonium ratio in the nutrient solutions (24). Toxic level of plasma oxalate has been associated with atherogenic activity through increasing the intracellular calcium concentration in endothelial cells and inhibition of endothelial proliferation (25). Although P. oleracea extract at the dose of $400 \mathrm{mg} / \mathrm{kg}$ has been used in some studies (26), but it seems that the lower doses would have the better safety profile with minor adverse effects.

The results of the present study also showed increasing in weight loss after administration of $P$. oleracea seeds extract in dexamethasone-induced hypertensive rats. The hypolipidemic effect and reducing body weight gain have been reported for $P$. oleracea in animal models of hyperlipidemia. Different biochemicals such as polyphenols, phytosterols, alkaloids and saponins may be responsible for antihyperlipidemic effect of this plant through decreasing food intake, increasing gastrointestinal motility, promoting insulin sensitivity, regulating the cell energy metabolism or reducing free fatty acids, reducing cholesterol absorption through interfering with its enterohepatic circulation and increasing cholesterol fecal excretion $(11,27)$.

\section{Conclusion}

The results of this study revealed that hydroalcoholic extract of $P$. oleracea seeds could not prevent dexamethasoneinduced hypertension. The presence of high amounts of catecholamines in this extract and increasing reactivity to vasopressor effects of catecholamines in dexamethasoneinduced hypertension may be accountable for increasing blood pressure in this animal model of hypertension.

\section{Authors' contributions}

All authors made substantial contributions to conception and design, and/or acquisition of data, and substantially to the writing of the manuscript. All authors read the final version and confirmed the manuscript publication.

\section{Conflict of interests}

The authors declare no conflicts of interest. The authors alone are responsible for the content of the paper.

\section{Ethical considerations}

All procedures were approved by the ethics committee of Isfahan University of Medical Sciences (IR.MUI. REC.1395.2.104).

\section{Funding/Support}

This study was financially supported by a research project No. 295104 from Isfahan University of Medical Sciences, Isfahan, Iran.

\section{References}

1. WHO. World health statistics. Geneva, Switzerland: WHO; 2015.

2. Kearney PM, Whelton M, Reynolds K, Muntner P, Whelton PK, He J. Global burden of hypertension: analysis of worldwide data. Lancet. 2005;365(9455):217-23. doi: 10.1016/s0140-6736(05)17741-1.

3. Hansson L, Zanchetti A, Carruthers SG, Dahlof B, Elmfeldt D, Julius S, et al. Effects of intensive bloodpressure lowering and low-dose aspirin in patients with hypertension: principal results of the hypertension optimal treatment (HOT) randomised trial. HOT Study Group. Lancet. $\quad$ 1998;351(9118):1755-62.

4. Evans RG, Kett MM, Shweta A, Fitzgerald SM, Denton KM, Eppel GA, et al. New physiological targets within the kidney for antihypertensive therapy. Drug Design Reviews Online. 2005;2(2):167-78. doi: 10.2174/1567269053202651.

5. Safaeian L, Ghannadi A, Javanmard SH, Vahidian MH. The effect of hydroalcoholic extract of Ferula foetida stems on blood pressure and oxidative stress in dexamethasoneinduced hypertensive rats. Res Pharm Sci. 2015;10(4):32634.

6. Elkhayat ES, Ibrahim SR, Aziz MA. Portulene, a new diterpene from Portulaca oleracea L. J Asian Nat Prod Res. 2008;10(11-12):1039-43. doi: 10.1080/10286020802320590.

7. Chan K, Islam MW, Kamil M, Radhakrishnan R, Zakaria MN, Habibullah $M$, et al. The analgesic and antiinflammatory effects of Portulaca oleracea L. subsp. Sativa (Haw.) Celak. J Ethnopharmacol. 2000;73(3):445-51.

8. Habtemariam S, Harvey AL, Waterman PG. The muscle relaxant properties of Portulaca oleracea are associated with high concentrations of potassium ions. J Ethnopharmacol. 1993;40(3):195-200.

9. Malek F, Boskabady MH, Borushaki MT, Tohidi M. Bronchodilatory effect of Portulaca oleracea in airways of asthmatic patients. J Ethnopharmacol. 2004;93(1):57-62. doi: 10.1016/j.jep.2004.03.015.

10. Lee AS, Lee YJ, Lee SM, Yoon JJ, Kim JS, Kang DG, et al. Portulaca oleracea ameliorates diabetic vascular inflammation and endothelial dysfunction in $\mathrm{db} / \mathrm{db}$ Mice. Evid Based Complement Alternat Med. 2012;2012:741824. doi: 10.1155/2012/741824.

11. Pragda SS, Kuppast IJ, Mankani KL, Ramesh L. Evaluation of antihyperlipidemic activity of leaves of Portulaca oleracea Linn against dexamethasone induced hyperlipidemia in rats. Int J Pharm Pharm Sci. 2012;4(4):279-83.

12. Chen T, Wang J, Li Y, Shen J, Zhao T, Zhang H. Sulfated modification and cytotoxicity of Portulaca oleracea L. polysaccharides. Glycoconj J. 2010;27(6):635-42. doi: 10.1007/s10719-010-9307-0.

13. Simopoulos AP, Norman HA, Gillaspy JE, Duke JA. Common purslane: a source of omega-3 fatty acids and antioxidants. J Am Coll Nutr. 1992;11(4):374-82.

14. Safaeian L, Ghasemi-Dehkordi N, Javanmard SH, Namvar H. Antihypertensive and antioxidant effects of a hydroalcoholic extract obtained from aerial parts of Otostegia persica (Burm.) Boiss. Res Pharm Sci. 2015;10(3):192-9.

15. Ong SL, Zhang Y, Whitworth JA. Mechanisms of dexamethasone-induced hypertension. Curr Hypertens Rev. 2009;5(1):61-74. doi: 10.2174/157340209787314315.

16. Russo D, Fraser R, Kenyon CJ. Dexamethasone therapy selectively increases the sensitivity to noradrenaline 
of the rat mesenteric circulation. J Hypertens Suppl. 1989;7(6):S126-7.

17. Zhang Y, Croft KD, Mori TA, Schyvens CG, McKenzie KU, Whitworth JA. The antioxidant tempol prevents and partially reverses dexamethasone-induced hypertension in the rat. Am J Hypertens. 2004;17(3):260-5. doi: 10.1016/j. amjhyper.2003.11.004.

18. Safaeian L, Hajhashemi V, Haghjoo Javanmard S, Sanaye Naderi H. The effect of protocatechuic acid on blood pressure and oxidative stress in glucocorticoid-induced hypertension in rat. Iran J Pharm Res. 2016;15(Suppl):83-91.

19. Parry O, Okwuasaba F, Ejike C. Effect of an aqueous extract of Portulaca oleracea leaves on smooth muscle and rat blood pressure. J Ethnopharmacol. 1988;22(1):33-44.

20. Kamil M, Jayaraj AF, Ahmad F, Gunasekhar C, Thomas S, Habibullah M, Chan K. Chemical standardization of Portulaca oleracea V. Sativa. J Pharm Pharmacol. 1998; 50(59):259-263.

21. Rasheed AN, Afifi FU, Shaedah M, Taha MO. Investigation of the active constituents of Portulaca oleraceae L. (Portulacaceae) growing in Jordan. Pak J Pharm Sci. 2004;17(1):37-45.

22. Yue ME, Jiang TF, Shi YP. Simultaneous determination of noradrenaline and dopamine in Portulaca oleracea L. by capillary zone electrophoresis. J Sep Sci. 2005;28(4):360-4. doi: $10.1002 /$ jssc. 200400045 .

23. Musa KY, Ahmed A, Ibrahim G, Ojonugwa OE, Bisalla M, Musa H, et al. Toxicity studies on the methanolic extract of Portulaca oleracea L. (Fam. Portulacaceae). J Biol Sci. 2007; 7(7):1293-95. doi: 10.3923/jbs.2007.1293.1295.

24. Fontana E, Hoeberechts J, Nicola S, Cros V, Battista Palmegiano G, Giorgio Peiretti P. Nitrogen concentration and nitrate/ammonium ratio affect yield and change the oxalic acid concentration and fatty acid profile of purslane (Portulaca oleracea L.) grown in a soilless culture system. J Sci Food Agric. 2006;86(14):2417-24. doi: 10.1002/ jsfa.2633.

25. Recht PA, Tepedino GJ, Siecke NW, Buckley MT, Mandeville JT, Maxfield FR, et al. Oxalic acid alters intracellular calcium in endothelial cells. Atherosclerosis. 2004;173(2):321-8. doi: 10.1016/j.atherosclerosis.2003.11.023.

26. Martins WB, Rodrigues SA, Silva HK, Dantas CG, Junior Wde L, Filho LX, et al. Neuroprotective effect of Portulaca oleracea extracts against 6-hydroxydopamine-induced lesion of dopaminergic neurons. An Acad Bras Cienc. 2016;88(3):1439-50. doi: 10.1590/0001-3765201620150574.

27. El-Newary SA. The hypolipidemic effect of Portulaca oleracea L. stem on hyperlipidemic Wister Albino rats. Annals Agricultural Sciences. 2016;61(1):111-24. doi: 10.1016/j.aoas.2016.01.002. 